\title{
Critérios Utilizados na Escolha do Livro Didático de Química por Professores da Educação Básica de Itacoatiara/AM
}

Criteria Used in the Choice of the Chemistry Textbook by Teachers of Basic Education in Itacoatiara/AM

Jean Michel dos Santos Menezes

Bárbara Samanta Almeida Pereira

Jelmir Craveiro de Andrade

Resumo: Haja vista que o livro didático se constitui ainda como um dos principais recursos didáticos utilizados pelos professores da Educação Básica, esse instrumento apresenta papel fundamental na escolha e evidência dos conteúdos a serem abordados nas aulas de Química. A discussão acerca da qualidade do livro didático ocupa papel de destaque no debate de políticas públicas voltadas à educação. Assim, objetivou-se com esta pesquisa identificar quais critérios os professores da Educação Básica de Itacoatiara/AM utilizam na escolha do livro didático de Química. Como participantes da pesquisa tivemos 10 professores de Química atuantes nas escolas públicas do município. Os dados foram coletados por meio de um questionário e uma entrevista semiestruturada. Pela análise dos dados foi possível perceber que os principais critérios utilizados pelos docentes estavam relacionados com a linguagem didática contida nos livros, a quantidade e qualidade dos exercícios neles contidos e a contextualização.

Palavras-chave: Livro didático, Ensino de química, Recurso didático.

Abstract: Whereas that the textbook is still one of the main didactic resources used by teachers of Basic Education, this instrument has a fundamental function in the choice and evidence of the contents to be addressed in Chemistry classes. The discussion about the quality of the textbook occupies a prominent role in the debate of public policies aimed at education. Thus, the objective of this research was to identify which criteria the teachers of Basic Education in Itacoatiara/AM use when choosing the Chemistry textbook. As research participants we had 10 Chemistry teachers working in public schools in the city. The data were collected through a questionnaire and a semistructured interview. By analyzing the data, it was possible to see that the main criteria used by the teachers were related to the didactic language contained in the books, the quantity and quality of the exercises contained therein and the contextualization.

Keywords: Textbook, Chemistry teaching, Didactic resource.

\section{Introdução}

O Livro Didático (LD) é um recurso pedagógico que visa à orientação das sequências didáticas e os conteúdos a serem ministrados em sala de aula pelos professores. Esse recurso surgiu com o intuito de ser uma versão "dinâmica" do conhecimento para fins escolares e/ou com o propósito de formação de valores, denominado como literatura didática técnica ou profissional (CHOPPIN, 2004). 
Nesse sentido, o LD é apresentado como guia curricular, orientador da prática docente, por vezes com maior influência sobre as ações dos professores do que os próprios referenciais curriculares. Assim, é necessário compreender suas potencialidades, limitações, critérios de escolha e influência sobre a prática educativa de professores (LOPES, 2005).

É rica a discussão sobre a pluralidade de fontes de informação com a qual convivemos atualmente. A televisão, os jornais, e principalmente a internet, permitem um fluxo contínuo, fácil e rápido de informações. Contudo, apesar das significativas contribuições das inovações tecnológicas no campo educacional, ainda se encontram em escolas públicas alunos que não possuem computador, smartphones ou ainda conexão com a internet, mas têm acesso aos LDs através das políticas públicas de seleção e distribuição desse recurso. Dessa forma, o LD se mantém como um dos principais meios de contato de professores e estudantes com os modelos conceituais do conhecimento científico (MAIA; VILLANI, 2016).

Atualmente, o LD é extensivamente utilizado e distribuído nas escolas da rede pública por meio do Programa Nacional do Livro Didático (PNLD), uma política pública proposta pelo Governo Federal que visa avaliar e a disponibilizar obras didáticas, pedagógicas e literárias, entre outros materiais de apoio à prática educativa, de forma sistemática, regular e gratuita (BRASIL, 2007).

Outro programa do Governo Federal implementado em 2004, o Programa Nacional do Livro Didático para o Ensino Médio (PNLEM), prevê a universalização de LD para os alunos do Ensino Médio público de todo o país. A escolha dos livros é feita por meio do Guia do Livro Didático (GLD), com o qual os professores das escolas públicas podem selecionar os livros de sua preferência para serem trabalhados trienalmente.

O GLD é um dos documentos mais importantes para efetivação da escolha, pois traz resenhas e informações acerca de cada uma das obras aprovadas no PNLD, apresentando aos professores análises, reflexões e orientações quanto ao conteúdo e estrutura das obras e suas potencialidades para a prática educacional. Cabe ao docente realizar a leitura do guia para 
identificar a coleção que melhor se adapta à sua metodologia e à proposta pedagógica da escola. Nesse processo é fundamental que o professor apresente uma leitura crítica que o permita planejar a utilização do LD a fim de relacionar os conhecimentos presentes no livro e os conhecimentos prévios dos estudantes.

Cada LD apresenta características especificas próprias das áreas de conhecimento ao qual se destinam, como por exemplo, nos livros da disciplina de Química encontram-se representações, exemplificação, imagens e textos que consideram a linguagem própria desta ciência.

O Livro Didático de Química (LDQ) vem sofrendo mudanças em sua abordagem pedagógica desde a década de $1930 \mathrm{com}$ a reforma de Francisco Campos. Essa reforma foi um grande marco para que o LDQ passasse a atender as demandas curriculares do ensino naquela época, contribuindo assim para sua evolução no que concerne ao processo de ensino e aprendizagem (CHAVES et. al, 2014).

O LDQ tem sido foco temático das pesquisas no Ensino de Química. As temáticas em destaque nessas pesquisas apresentam: relação do livro didático com as produções curriculares nas escolas, mais especificamente em termos que vão desde a produção e comercialização, até a qualidade gráfica e adequação dos conteúdos (LAJOLO, 1996; LOUGUERCIO et al., 2001; OTESBELGUE et al., 2013; MAIA; VILLANI, 2016).

Dada a importância do LD no processo de ensino e aprendizagem, propomos um olhar atencioso sobre a relação do professor com esse recurso, objetivando identificar quais critérios os professores de Química da Educação Básica do município de Itacoatiara/AM utilizam na escolha do LDQ.

\section{Percurso Metodológico}

O presente estudo apresentou caráter qualitativo, visando explorar as características dos indivíduos e contextos que não podem ser prontamente descritos numericamente. A pesquisa qualitativa é descritiva, interpretativa, utiliza o método indutivo e foca principalmente no processo e nas perspectivas dos indivíduos sociais envolvidos, como gestores, professores, alunos etc, 
utilizando principalmente métodos que possibilitam a obtenção de dados descritivos, como entrevistas, observações, questionários e outros. (MASSONI, 2016).

A coleta de dados foi realizada na cidade de Itacoatiara, localizada na Região Metropolitana de Manaus, no estado do Amazonas. É a terceira cidade mais populosa do estado e possui um total de 15 escolas estaduais, sendo 13 escolas na zona urbana e 2 na zona rural. A pesquisa foi autorizada pelo Comitê de Ética e Pesquisa (CEP) da Universidade Federal do Amazonas (UFAM), com o número de parecer de aprovação 4.539.819.

Participaram do estudo 10 professores de Química atuantes nas escolas da rede pública de ensino (codificados de P1 a P10). Esses participantes responderam a um questionário misto e participaram de uma entrevista semiestruturada. Vale ressaltar que a coleta de dados se deu no segundo semestre de 2020, sendo realizada totalmente de maneira remota, utilizando ambientes virtuais, devido a pandemia da Covid-19.

O primeiro instrumento de coleta de dados utilizado, o questionário, é definido por Sampieri et al. (2013) como um conjunto de perguntas a respeito de uma ou mais variáveis que serão mensuradas em uma pesquisa, devendo ser coerente com a formulação do problema e a hipótese. O conteúdo das questões que compõem esse instrumento é tão variado quanto os aspectos que mensura, sendo considerados dois tipos de questões: fechadas e abertas.

O questionário respondido pelos participantes foi adaptado de Maia et. al. (2011) e Farias (2018), organizado com um total de 10 questões abertas e fechadas. Desse total de questões, para este artigo serão utilizados os dados referente a 5 delas, apresentadas no Quadro 1.

Quadro 01 - Questionário respondido pelos professores participantes.

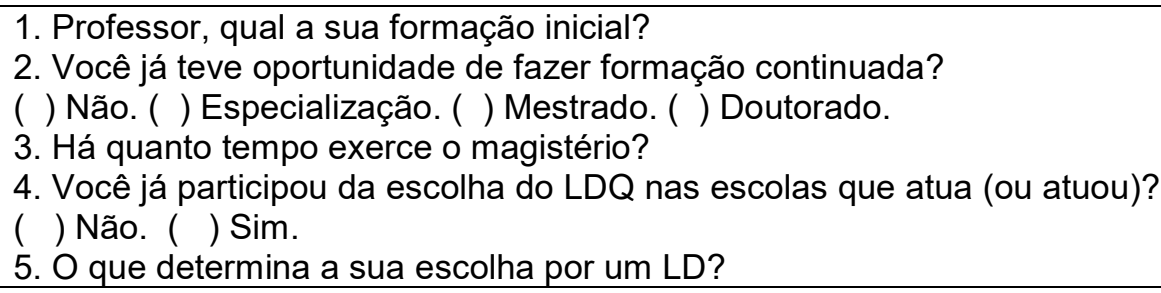

Fonte: Elaborado pelos autores. 
O outro instrumento de coleta de dados utilizado foi a entrevista, com o intuito de complementar os dados do questionário e realizar a triangulação dos resultados da pesquisa. A entrevista pode ser definida como uma conversa a dois, ou entre vários interlocutores, realizada por iniciativa do entrevistador e sempre dentro de uma finalidade, proporcionando ao entrevistador, verbalmente, informações pertinentes com vistas a um objetivo de pesquisa (MINAYO, 2016; SZYMANSKI, 2018).

Minayo (2016) classifica as entrevistas em: a) sondagem de opinião; b) semiestruturada; c) aberta ou em profundidade; d) focalizada; e) projetiva. Levando em consideração as características de cada tipo, adotou-se para a presente pesquisa a entrevista semiestruturada, na qual o entrevistado tem a possibilidade de discorrer sobre o tema em questão a partir de questões abertas ou fechadas. O roteiro de entrevista foi adaptado de Maia e Villani (2016), contemplando um total de 6 perguntas abertas, das quais 3 foram selecionadas para compor a discussão deste trabalho (Quadro 2).

Quadro 02 - Roteiro de entrevista utilizado para este trabalho.

Data: _____, Hora: 00:00

1. Qual sua formação na graduação. Houve alguma disciplina na sua graduação que você trabalhou o livro didático?

2. Professor, você conhece ou já ouviu falar sobre o PNLD? Comente sua resposta.

3. Quais critérios você adota para escolher o LDQ para desenvolver suas atividades em sala de aula?

Você teria algo a acrescentar ou alguma dúvida?

Fonte: Elaborado pelos autores.

\section{Resultados e Discussão}

Parte do questionário se voltava a traçar o perfil profissional dos participantes, visando identificar a sua formação inicial e continuada, o tempo que exercem a sua profissão e a sua experiência em relação ao processo de escolha do LDQ.

Com relação à formação inicial dos professores (Figura 01), identificouse que 6 dos professores possuem graduação em Licenciatura em Ciências: Química e Biologia (curso ofertado na unidade da Universidade Federal do Amazonas localizada no município). Alguns docentes cursaram pósgraduações, sendo 5 especialistas e 2 mestres. 
Figura 01 - Formação inicial dos docentes participantes.

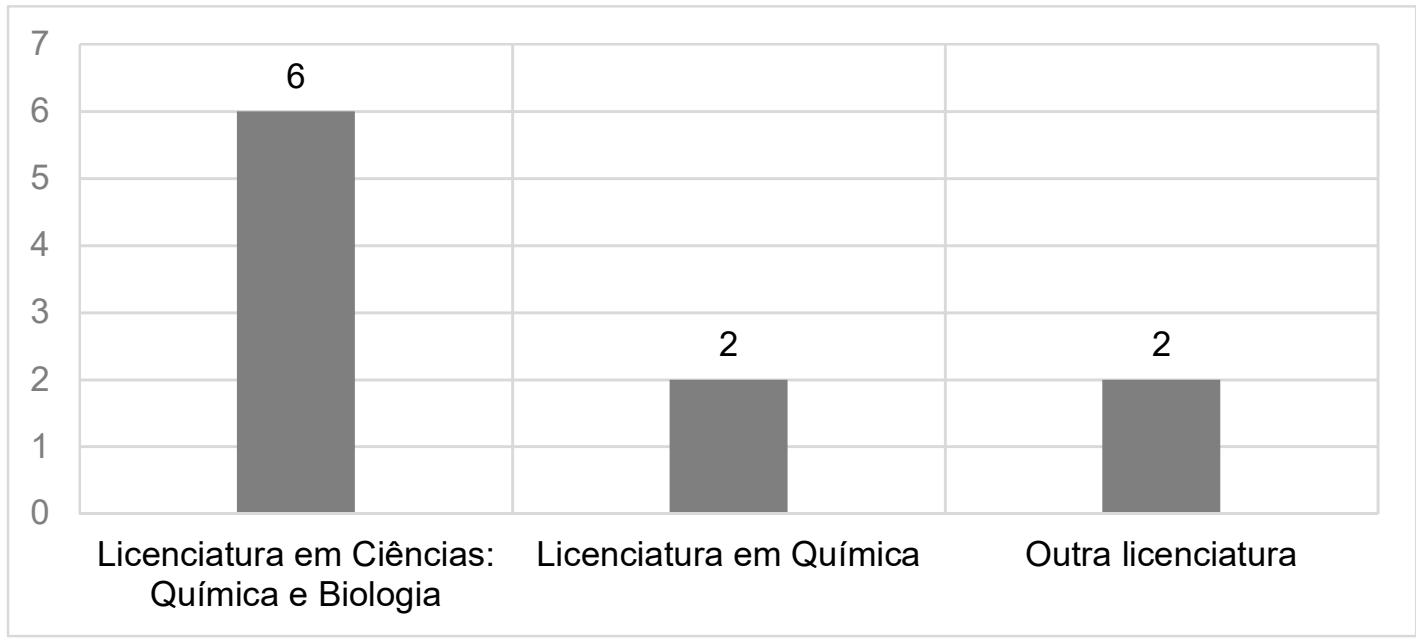

Fonte: Elaborada pelos autores.

Além de informações sobre a formação dos docentes, foi possível identificar há quanto tempo os participantes exercem a profissão (Figura 02).

Segundo Rosa e Mohr (2016) o professor em período inicial do exercício da sua profissão vai aprendendo a escolher e utilizar o LD ao longo de suas atividades profissionais, ou seja, o docente aprende a escolher o LD ao longo de sua vivência no magistério. Na sua pesquisa os autores observaram que quanto maior o tempo de atividade do docente, mais capaz ele se considera para fazer a seleção do LD com que trabalha, o que o auxilia em todo esse processo.

Figura 02 - Tempo de exercício da docência.

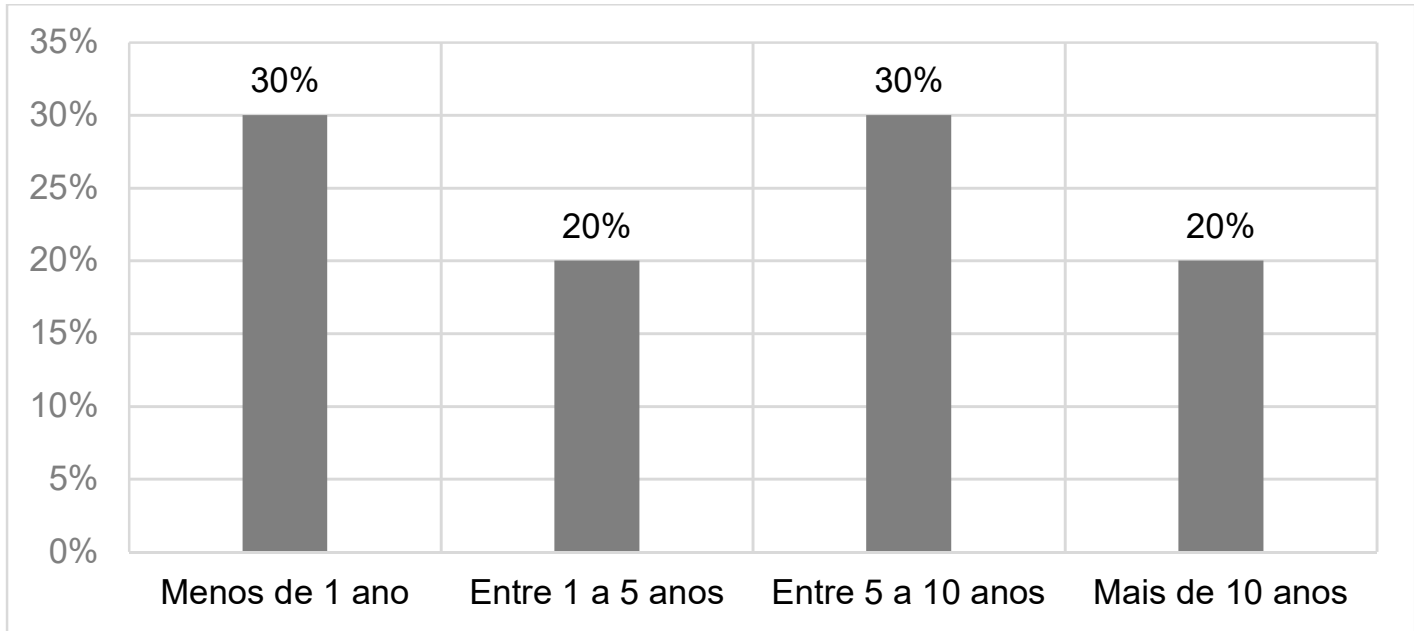

Fonte: Elaborada pelos autores. 
Apenas 4 professores já haviam participado do processo de escolha do LDQ em algum momento. Ao instigá-los sobre o GLD e o PNLD percebeu-se que todos eles já ouviram falar sobre o programa, porém não conhecem detalhes do processo, como é possível perceber na fala de um entrevistado:

P10: "[...] já ouvi falar sim, mas eu não tenho muitas informações, eu sei que é um programa que é para distribuir o livro didático nas escolas 'né', e para 'tá' atualizando esses livros, três em três anos [...]"

O conhecimento acerca desses documentos é fundamental, pois orienta os docentes para que possam melhor realizar o processo de escolha das obras que serão utilizadas nas escolas. O GLD, por exemplo, dispõe orientações, informações e reflexões, de modo a levar o professor a sentir-se fundamentado na apreciação e decisão sobre as obras que melhor possam contribuir para o desenvolvimento de suas atividades didáticas. Por isso, é importante conhecer, acompanhar e refletir sobre o PNLD, em seu amplo espectro.

Em relação aos critérios utilizados pelos professores para a escolha do LDQ, a Tabela 01 apresenta as categorias e respectivas frequências que correspondem aos critérios citados.

Tabela 01 - Categorias e frequências referentes aos critérios citados pelos docentes.

\begin{tabular}{|l|l|}
\hline Categoria & Frequência \\
\hline Linguagem Didática & 50 \\
\hline Exercícios & 50 \\
\hline Contextualização & 30 \\
\hline Experimentos & 20 \\
\hline $\begin{array}{l}\text { Relação com Documentos } \\
\text { Oficiais }\end{array}$ & 10 \\
\hline
\end{tabular}

Fonte: Elaborada pelos autores.

As categorias com maior frequência foram Linguagem Didática e Exercícios, ambas com $50 \%$. Dentro da primeira categoria podemos destacar a fala do professor $\mathrm{P} 1$, que representa bem este critério, pois para grande parte dos docentes o LDQ necessita de uma linguagem "fácil", "objetiva", "simples". 
P1: "O critério que eu busco é que o livro apresente uma linguagem simples e fácil [...] para facilitar o entendimento dos alunos a respeito do assunto abordado porque a gente sabe que a Química ela exige muita atenção e interpretação pessoal $[\ldots] "$

De acordo com Lima e Silva (2010), podemos inferir que a linguagem chamada de simples e fácil pelos professores, é na maioria das vezes aquela que aborda superficialmente os fenômenos com pouca ou baixa relativização deles, ou ainda a simplificação demasiada dos conceitos científicos, o que pode atrapalhar a construção do conhecimento.

Em relação a categoria Exercícios, que englobou respostas que faziam menção à palavra "exercícios" ou "questões", destaca-se o seguinte trecho:

\section{$\mathrm{P} 1:$ "[...] aqueles livros que contém bastante exercícios [...]"}

Os professores não descreveram a natureza ou o caráter desses exercícios, apenas sinalizaram sobre a quantidade alta que deveria estar presente no livro escolhido e que deviam ser "bem elaborados", mas não informaram o sentido dessa elaboração.

Em grande parte das unidades escolares os professores ainda centram suas expectativas na aprovação dos estudantes no exame de vestibular, enfatizando conceitos químicos, priorizando leis, teorias e memorização de fórmulas, o que não é de todo ruim, porém é característico da realização exaustiva de exercícios, prejudicando a prática educativa (MAIA et al., 2011; LEITE; SOARES, 2018).

Outro critério que vale a pena destacar, refere-se a categoria Contextualização, com frequência de $30 \%$, na qual os professores relatam que buscam no LDQ as relações da Química com o cotidiano do educando.

P6: "Conteúdos contextualizados com a realidade dos alunos."

A grande maioria dos professores compreendem 0 ensino contextualizado como "tirar aquela teoria toda do livro, a teoria por traz da Química e aplicar essa teoria em prática, dando exemplo daquilo que os alunos fazem no dia a dia" (P4), limitando-se a ideia de contextualização ao uso de exemplos do cotidiano. 
Vale destacar o que dizem Wartha et al. (2013), destacando a contextualização como um princípio norteador para o ensino de Ciências, o que significa um entendimento mais complexo do que a simples exemplificação ou apresentação superficial de contextos sem uma problematização que de fato instigue a busca da compreensão sobre os temas em estudo.

Segundo Silva e Marcondes (2010), no ensino de Química, a contextualização pode ser compreendida de maneira geral como o estudo de questões sociais para o desenvolvimento de atitudes e valores, e o estudo das questões sociais visando à transformação do meio social.

A contextualização no LD é um desafio a todas as áreas do conhecimento, no que se refere à sua distribuição nacional, pois não é possível adequar-se plenamente a todos os contextos que envolve um país com tão grandes dimensões como é o Brasil (FARIAS, 2018). Desse modo, cabe ao docente analisar o livro que mais se adequa a sua realidade e possibilita a abertura para o trabalho com a regionalidade.

Além das categorias já discutidas, outras duas foram identificadas com pouca frequência pelos professores, correspondendo a $20 \%$ e $10 \%$. Essas se referem a Experimentos e a Relação com Documentos Oficiais, respectivamente.

Em relação a categoria Experimentos, temos o seguinte trecho característico:

P2: "Bons exercícios e experimentos"

Em nenhum momento foi possível identificar a natureza das atividades experimentais destacadas pelos docentes pesquisados, ou seja, se são de caráter investigativo ou demonstrativo por exemplo, ou ainda se são com materiais de baixo custo e adaptável a espaços além do laboratório. De acordo com Maia e colaboradores (2011) isso pode demonstrar que os professores parecem não compreender o real papel da experimentação no ensino de Química, uma vez que só a existência de experimentos pode ser suficiente para a adoção do LD.

Para Leite (2018) e Silva e Rezende (2020), é fundamental desenvolver propostas de experimentos adequadas no livro que ajudem a superar visões 
errôneas envolvendo as atividades experimentais. O uso de experimentos de caráter investigativo, por exemplo, favorece o processo de construção de um problema, o debate, levantamento de hipóteses, a avaliação de evidências, entre outras características dessa abordagem.

Desse modo, espera-se que os experimentos propostos nos LDQ, não sejam utilizados para apenas comprovar a teoria ou motivar os alunos, mas que possam ter um objetivo pedagógico importante no ensino e na compreensão da ciência.

A categoria Relação com Documentos Oficiais foi representada por meio da resposta dada pelo professor P7.

\section{P7: "Componente Curriculares de acordo com os PCN's."}

Em relação a este último critério, pode-se inferir que a baixa frequência nesta categoria pode ser interpretada como uma atitude de resistência, discordância, falta de conhecimento sobre as orientações oficiais, ou ainda a ideia de que todos os LDQ atuais já inserem essas orientações - que hoje não mais são os PCNs, mas sim a Base Nacional Comum Curricular (BNCC) - e, portanto, isso não diferencia um livro de outro ou ainda, o desconhecimento da polissemia das orientações de governo, isto é, diferentes modos de compreendê-las e de traduzi-las em texto didático. Além disso nenhum professor fez menção a BNCC ou sobre as competências e habilidades possíveis de serem trabalhadas a partir do uso do LDQ.

\section{Considerações Finais}

A escolha do LDQ a ser adotado na escola não é uma tarefa fácil para os professores. Por isso, devido à variedade de obras que possam vir a ser utilizadas durante as aulas, sua escolha deve ser feita de forma criteriosa, considerando diferentes aspectos relacionados à sua funcionalidade pedagógica.

A partir dos resultados obtidos podemos tecer algumas considerações a respeito dos critérios citados pelos docentes pesquisados. Os principais critérios utilizados pelos professores de Química de Itacoatiara/AM para 
escolha do LDQ estavam relacionados com a linguagem didática, os exercícios nele contemplados e a relação dos conteúdos com o cotidiano do aluno. Poucos citaram a experimentação e não foram mencionadas as orientações do documento educacional oficial vigente, a BNCC.

De acordo com Lima e Silva (2010), o professor nem sempre faz sua escolha após um exame minucioso das obras disponíveis. Quase sempre deixa-se influenciar pela pressão das editoras mais conhecidas, do colegiado e, muitas vezes, pelos companheiros de profissão que geralmente adotam o mesmo autor que já vem sendo utilizado.

O livro didático é um recurso que auxilia o professor no desenvolvimento de uma proposta de ensino e aprendizagem que atenda às necessidades educacionais. Assim, além de apresentar ao professor LDQs alternativos e variados, é importante que haja investimento na formação inicial e continuada do professor para que adquira segurança quanto a seleção e utilização desses materiais.

Diante do exposto, acreditamos que essa pesquisa possa contribuir para estudos relacionados a formação inicial e continuada de professores de Química do Ensino Médio no que diz respeito a escolha e utilização do LD.

\section{Referências}

BRASIL. Ministério da Educação. Secretaria de Educação Básica. Equipamentos e materiais didáticos. Brasília: Universidade de Brasília, 2007.

CHOPPIN, A. História Dos Livros e das Edições Didáticas: Sobre o Estado da Arte. Educação e Pesquisa, v. 30, n. 3, p. 549-566, 2004. Disponível em: <https://www.revistas.usp.br/ep/article/view/27957> Acesso em: 20 jan 2021.

FARIAS, G. B. Contextualização, Práticas Educativas e o Livro Didático no Ensino de Química. 2018. 87 f. Dissertação (Mestrado em Ensino de Química) - Universidade Federal do Amazonas, Manaus. 2018.

LAJOLO, M. P. Livro didático: Um (quase) Manual de Ensino. Em Aberto, v. 16, n. 69, p. 40-49, 1996. Disponível em: <https://doi.org/10.24109/21766673.emaberto.16i69.2061> Acesso em: 20 dez 2020.

LEITE, B. S. A Experimentação no Ensino de Química: Uma Análise das Abordagens nos Livros Didáticos. Educación Química, v. 29, n. 3, p. 61782018. 
<http://dx.doi.org/10.22201/fq.18708404e.2018.3.63726>. Acesso em: 18 jan 2021.

LEITE, M. B.; SOARES, M. H. F. B. Cálculos Químicos nos Capítulos de Solução e Estequiometria em Livros Didáticos de Química Aprovados pelo PNLD/2012/2015. Educação Química em Punto de Vista, v. 2, n. 1, p. 41-60 2018. Disponível em: <https://doi.org/10.30705/eqpv.v2i1.983>. Acesso em: 20 dez 2020.

LIMA, M. E. C. C.; SILVA, P. S. Critérios que Professores de Química Apontam como Orientadores da Escolha do Livro Didático. Ensaio, v. 12, n. 2, p. 121136, $2010<$ https://periodicos.ufmg.br/index.php/ensaio/article/view/10352> Acesso em: 19 dez 2020.

LOPES, C. E.; MEIRELLES, E. O Desenvolvimento da Probabilidade e da Estatística. XVIII Encontro Regional de Professores de Matemática Lem/Imecc/Unicamp. Anais... Campinas - SP; 2005, p. 1-8. Disponível em: $<$ https://www.ime.unicamp.br/erpm2005/anais/m_cur/mc02_b.pdf > Acesso em: 15 jan 2021.

LOGUERCIO, R. Q.; SAMRSLA, V. E. E.; DEL PINO, J. C. A Dinâmica de Analisar Livros Didáticos com os Professores de Química. Química Nova, v. 24, n. 4, p. 557-5622001. Disponível em: <http://quimicanova.sbq.org.br/detalhe_artigo.asp?id=717> Acesso em: $20 \mathrm{dez}$ 2020.

LUDKE, M., ANDRÉ, M. E. D. A. Pesquisa em Educação: Abordagens Qualitativas. São Paulo: EPU, 2013.

MAIA, J. O.; SÁ, L. P.; MASSENA, E. P.; WARTHA, E. J. O Livro Didático de Química nas Concepções de Professores do Ensino Médio da Região Sul da Bahia. Química Nova na Escola, v. 33, n. 2, p. 115-124, 2011. Disponível em: < http://qnesc.sbq.org.br/online/qnesc33_2/07-PE7110.pdf> Acesso em: 21 jan 2021.

MAIA, J. O.; VILLANI, A. A Relação de Professores de Química com o Livro Didático e o Caderno do Professor. Revista Electrónica de Enseñanza de las Ciencias, v. $15, \quad$ n. $1, \quad$ p. 121-146, 2016. Disponível em: <http://reec.uvigo.es/volumenes/volumen15/REEC_15_1_7_ex969.pdf> Acesso em: 21 jan 2021.

MASSONI, N. T. A Entrevista: Uma Técnica Útil à Coleta de Dados em Pesquisa Qualitativa. In: MASSONI, N. T.; MOREIRA, M. A. (Orgs.) Pesquisa Qualitativa em Educação em Ciências: Projetos, Entrevistas, Questionários, Teoria Fundamentada, Redação Científica. São Paulo: Editora Livraria da Física, 2016.

MINAYO, M. C. S. Trabalho de Campo: Contexto de Observação, Interação e Descoberta. In: MINAYO, M. C. S. (Org.). Pesquisa Social: Teoria, Método e Criatividade. Petrópolis: Vozes, 2015. 
OSTESBELGUE, R.; SCHRÖDER, A. H.; DIAS, A. M.; ALBRECHT, L. D.; DUBOW, M.; FERREIRA, M. Programa Nacional do Livro Didático e a Análise de Livros Didáticos de Química. In: 33o EDEQ, UNIJUí, 2013. Disponível em: <https://www.publicacoeseventos.unijui.edu.br/index.php/edeq/article/view/2778 /2352> Acesso em 21 jan 2021.

ROSA, M. D.; MOHR, A. Seleção e Uso do Livro Didático: Um Estudo com Professores de Ciências na Rede de Ensino Municipal de Florianópolis. Revista Ensaio em Educação em Ciências, v. 18, n. 3, p. 97-115, 2016. Disponível em: <https://www.redalyc.org/articulo.oa?id=129549111005> Acesso 21 jan 2021.

SAMPIERI, R. H.; COLLADO, C. F.; LUCIO, M. P. B. Metodologia da Pesquisa. Porto Alegre: Penso, 2013.

SILVA, A. C. A.; REZENDE, P. B. Análise dos Livros Didáticos de Química: Compreendendo os Roteiros Experimentais de Extrato de Repolho Roxo. Revista Debates em Ensino de Química, v. 6, n. 2, p. 178-193, 2020. Disponível em: <http://www.journals.ufrpe.br/index.php/REDEQUIM/article/view/3478> Acesso em: 21 fev 2021.

SILVA, E. L.; MARCONDES, E. E. R. Visões de Contextualização de Professores de Química na Elaboração de seus Próprios Materiais Didáticos. Ensaio, v. 12, n 1, p. 101-118, 2010. Disponível em: <https://periodicos.ufmg.br/index.php/ensaio/article/view/10372> Acesso em: 21 jan 2021.

SZYMANSKI, H. Entrevista Reflexiva: Um Olhar Psicológico sobre a Entrevista em Pesquisa. In: SZYMANSKI, H.; ALMEIDA, L. R.; PRANDINI, R. C. A. R. (Orgs.). A Entrevista na Pesquisa em Educação: A Prática Reflexiva. Campinas: Autores Associado, 2018.

WARTHA, E. J.; SILVA, E. L. e BEJARANO, N. R. R. Cotidiano e Contextualização no Ensino de Química. Química Nova na Escola, v. 35, n. 2, p. 84-91, 2013. Disponível em: <http://dx.doi.org/10.13140/RG.2.1.3627.0243> Acesso em: 05 maio 2021.

\section{Sobre os Autores}

\section{Jean Michel dos Santos Menezes}

jmichelmenezes@gmail.com

Docente do Ensino Superior do Instituto de Ciências Exatas e Tecnologia (ICET) da Universidade Federal do Amazonas (UFAM), Itacoatiara. Mestre em Ensino de Química pela Universidade Federal do Amazonas. 


\section{Bárbara Samanta Almeida Pereira}

samantabarbara4@gmail.com

Estudante de graduação do curso de Licenciatura em Ciências: Química e Biologia no Instituto de Ciências Exatas e Tecnologia (ICET) da Universidade Federal do Amazonas (UFAM).

Jelmir Craveiro de Andrade

jelmirandrade@outlook.com

Mestre em Química Analítica pela Universidade Federal do Amazonas (UFAM). Licenciado em Química pela Faculdade Metropolitana de Manaus (FAMETRO). 